\title{
STRATEGI PENGEMBANGAN KOPERASI PETERNAK GALUR MURNI DI KABUPATEN JEMBER
}

\author{
Dany Alifah Irawati ${ }^{*}$, Musa Hubeis ${ }^{* *}$, dan Muksin ${ }^{* * *}$ \\ ${ }^{*}$ SMK Negeri I Maesan, Kabupaten Bondowoso \\ Jl. Sukowono, Sumbersari, Maesan, Bondowoso 68262 \\ **) Departemen Manajemen, Fakultas Ekonomi dan Manajemen, Institut Pertanian Bogor \\ Jl. Kamper Wing 4 Level 5 Kampus IPB, Bogor, Jawa Barat 16680 \\ ${ }^{* * *}$ Program Studi Manajemen Agribisnis, Politeknik Negeri Jember \\ Jl. Mastrip PO BOX 164 Jember 68101
}

\begin{abstract}
The objective of the research is to identify the internal and external environment condition in (Galur Murni Cattle breeder cooperation), Koperasi Peternak Galur Murni to analyze the strategic alternative to be implemented in the development of Koperasi Peternak Galur Murni and to prioritize development strategy of Koperasi Peternak Galur Murni in the future. The analysis covered descriptive analysis, Internal Factor Evaluation (IFE), External Factor Evaluation (EFE), Internal-External (IE) matrix analysis, Strengths, Weaknesses, Opportunities and Threat (SWOT) and Analytical Hierarchy Process (AHP). The result shows that the strategic factor that becomes the main strength with relatively high importance is Quality Control system for milk received from the farmers. The alternative strategy that can be implemented in KPGM is increasing the promotion activities by socializing the importance of drinking milk, production activities efficiency by arranging a Standard Operational Procedure (SOP), strengthening of cooperation, registering the product to Food and Drug Control Agency/Badan Pengawas Obat dan Makanan (BPOM), conducting intensive communication with all the cooperation members, using the appropriate technology in production activities, diversification of products, strengthening the modal through loan and coordinating with the government to get assistance in strengthening the cooperation and breeder. The AHP results shows that the strategic priority is 1) the strengthening of the modal through financial institution, 2) increasing the promotion activities by socializing the importance of drinking milk, 3) product diversification and 4) conducting coordination with the local government and animal husbandry department and UMKM department
\end{abstract}

Keywords: cooperation breeder pure lines, development strategy, IFE, EFE, SWOT

\begin{abstract}
ABSTRAK
Penelitian ini bertujuan mengidentifikasi kondisi lingkungan internal dan eksternal Koperasi Peternak Galur Murni, menganalisis alternatifstrategi yang dapat diterapkan dalam pengembangan Koperasi Peternak Galur Murni, dan menentukan prioritas strategi pengembangan Koperasi Peternak Galur Murni di masa datang. Metode analisis data yang digunakan meliputi analisis deskriptif, analisis Internal Factor Evaluation (IFE), External Factor Evaluation (EFE), analisis matrik Internal-External (IE), Strengths, Weaknesses, Opportunities dan Threats (SWOT) dan Analytical Hierarchy Process (AHP). Hasil penelitian menunjukkan faktor strategik yang menjadi kekuatan utama dengan kepentingan relatif tertinggi adalah sistem Quality Control (QC) untuk peneriman susu dari peternak. Alternatif strategi yang dapat diterapkan di KPGM adalah peningkatan kegiatan promosi dengan sosialisasi pentingnya minum susu, efisiensi kegiatan produksi dengan penyusunan Standard Operational Procedure (SOP), penguatan kelembagaan koperasi, melakukan pendaftaran produk ke Badan Pengawas Obat dan Makanan (BPOM), melakukan komunikasi intensif dengan semua anggota koperasi, pemanfaatan teknologi tepat guna dalam kegiatan produksi, diversifikasi produk, penguatan permodalan melalui pinjaman selain lembaga keuangan dan melakukan koordinasi dengan pemerintah daerah untuk bantuan penguatan koperasi dan peternak. Hasil analisis AHP, strategi prioritasnya adalah 1) penguatan modal melalui lembaga keuangan, 2) peningkatan kegiatan promosi dengan sosialisasi pentingnya minum susu, 3) diversifikasi produk, dan 4) melakukan koordinasi dengan Pemerintah Daerah serta Dinas Peternakan dan Dinas UMKM.
\end{abstract}

Kata kunci: koperasi peternak galur murni, strategi pengembangan, IFE, IFE, SWOT

${ }^{1}$ Alamat Korespondensi:

Email: dany.alifah.polije@gmail.com 


\section{PENDAHULUAN}

Peternakan sapi perah nasional menghadapi tantangan dari negara-negara maju dalam produk susu. Hal ini terlihat dari pemenuhan susu dalam negeri yang saat ini masih bergantung pada impor. Perkembangan produksi dan harga susu menunjukkan komoditas yang penting, hal ini ditandai dengan meningkatnya jumlah produksi, mutu dan fluktuasi harga. Menurut data Kementerian Perindustrian (2013), beberapa bulan terakhir Indonesia mengalami permasalahan mengenai defisit total kebutuhan bahan baku susu sebanyak 3.3 juta ton per tahun, sedangkan pasokan dari peternak hanya 690,000 ton. Artinya, hanya $21 \%$ bahan baku industri susu olahan yang bisa dipenuhi oleh peternak, sedangkan 79\% masih harus diimpor. Karakteristik pelaku industri susu di Indonesia lebih memihak susu impor, karena susu impor lebih baik dari segi mutu dan konsistensi kuantitas untuk kebutuhan produksinya.

Proses pemasaran susu segar yang baik merupakan salah satu prasyarat pengembangan usaha peternakan sapi perah. Keterbatasan para peternak sapi perah dalam menyediakan saluran pemasaran yang baik, telah mengakibatkan mereka beraliansi dalam format koperasi. Baga (2005) menyatakan bahwa secara umum terdapat banyak alasan yang menyebabkan koperasi menjadi hal yang dibutuhkan bagi pengembangan pertanian. Ditinjau dari segi kuantitas perkembangan koperasi di Indonesia saat ini sangat menggembirakan, tetapi dilihat dari segi kualitas masih memprihatinkan. Hal tersebut dapat disebabkan karena adanya masalahmasalah yang dihadapi koperasi, antara lain pada aspek kelembagaan yang meliputi kepercayaan dan partisipasi anggotanya yang belum optimal, alat kelengkapan organisasi (Rapat Anggota, Pengurus dan Badan Pengawas) yang belum sepenuhnya berfungsi dengan baik, dan masalah pengawasan yang belum memadai (Anoraga dan Widiyanti 2007). Selain aspek tersebut, aspek usaha juga merupakan suatu permasalahan bagi koperasi, yaitu belum mampu memanfaatkan peluang usaha dengan baik yang disebabkan mutu pengelola dan sarana usaha yang kurang memadai serta lemahnya permodalan. Permasalahan tersebut diantaranya dapat diatasi melalui pengembangan koperasi. Anoraga dan Widiyanti (2007) menyatakan bahwa ada dua upaya terobosan yang perlu ditempuh untuk mempercepat pengembangan koperasi, yaitu memberikan akses lebih besar kepada koperasi dalam mendapatkan modal usaha, serta dilakukan penyesuaian terhadap peraturan dan perundang-undangan yang berlaku dalam dunia usaha.

Koperasi Peternak Galur Murni (KPGM) merupakan salah satu koperasi susu yang terdapat di Kabupaten Jember, Propinsi Jawa Timur. Koperasi ini berdiri sejak tahun 1999, tetapi baru tahun 2010 memiliki fokus pada pemeliharaan sapi perah. Unit usaha yang dikelola oleh KPGM adalah penjualan susu segar ke Industri Pengolahan Susu (IPS), susu pasteurisasi dan yogurt serta simpan pinjam. Sebagai sebuah badan usaha berbentuk koperasi, KPGM didirikan untuk membantu meningkatkan kesejahteraan para anggotanya. Keberadaan KPGM di Kabupaten Jember sangat penting bagi keberlanjutan usaha para peternak sapi perah, sebab melalui wadah koperasi inilah seluruh hasil produksi susu sapi peternak dapat tersalurkan kepada konsumen. Permasalahan yang dihadapi Peternak Galur Murni adalah sulitnya mendapatkan pinjaman modal, produksi susu segar yang semakin turun, fasilitas produksi yang masih sederhana dan ketergantungan pada penjualan susu segar. Dengan adanya berbagai permasalahan tersebut maka koperasi diharapkan mampu menjawab masalah dari Peternak Galur Murni sehingga perlu merumuskan prioritas strategi dalam pengembangannya di masa datang dengan menganalisis alternatif strategi yang dapat diterapkan, berdasarkan identifikasi kondisi lingkungan internal dan eksternal KPGM.

Beberapa penelitian terdahulu yang menjadi referensi untuk penelitian ini terdiri dari penelitian yang berkaitan dengan strategi pengembangan menggunakan analisis SWOT diantaranya Kasim et al. (2011), Sarpintono, (2013), Adinata et al. (2012). Penelitian dengan alat analisis Analytic Hierarchy Process (AHP) dilakukan juga oleh Tampubolon (2011), Muzammil AR (2005), dan Azhim et al. (2014).

Tujuan dari penelitian ini adalah mengidentifikasi kondisi lingkungan internal dan eksternal KPGM, menganalisis alternatif strategi yang dapat diterapkan dalam pengembangan KPGM, dan menentukan prioritas strategi dalam pengembangan KPGM di masa datang. 


\section{METODE PENELITIAN}

Penelitian ini merupakan studi kasus yang dilakukan di KPGM, Dusun Sadengan, Desa Rowotengah, Kecamatan Sumberbaru Kabupaten Jember Propinsi Jawa Timur. Data yang dikumpulkan meliputi data primer dan sekunder. Data primer diperoleh langsung dari lokasi penelitian melalui dua metode, yaitu wawancara dan dokumentasi. Pada wawancara ini, dimungkinkan peneliti dengan responden melakukan tanya jawab secara interaktif maupun secara sepihak saja misalnya dari peneliti saja (Sukardi, 2009). Cara lain untuk memperoleh data dari responden adalah menggunakan teknik dokumentasi. Pada teknik ini, peneliti dimungkinkan memperoleh informasi dari bermacam-macam sumber tertulis atau dokumen yang ada pada responden atau tempat, di mana responden bertempat tinggal atau melakukan kegiatan sehariharinya (Arikunto, 2006). Teknik penentuan responden pakar dilakukan secara purposive sampling yang didasarkan atas pertimbangan keahlian responden. Responden berjumlah enam orang, yaitu 1) Ketua KPGM, 2) Manajer KPGM, 3) Dinas Koperasi, 4) Dinas Peternakan, 5) Peternak dan 6) Dosen Politeknik Negeri Jember. Data sekunder merupakan data yang diperoleh dari arsip koperasi, literatur serta referensi dari dalam dan luar KPGM

Teknik pengolahan dan analisis data yang digunakan melalui tiga tahapan analisis, yaitu tahap masukan dengan analisis deskriptif menggunakan pendekatan non finansial yang meliputi aspek pasar, aspek teknis, aspek manajemen, aspek sosial lingkungan, aspek hukum dan aspek ekonomi. Hasil dari analisis deskriptif aspek-aspek tersebut dijadikan pertimbangan untuk melakukan identifikasi terhadap lingkungan koperasi untuk mendapatkan faktor-faktor internal dan eksternal. Tahap selanjutnya adalah tahap sinkronisasi, yang memfokuskan pada hasil strategi dengan memadukan faktor-faktor internal dan eksternal. Pada tahap ini dilakukan analisis matriks IE. Selanjutnya, dilakukan penetapan strategi pengembangan menggunakan analisis matriks SWOT dengan mempertimbangkan IFE dan EFE yang telah dibuat. Hasil dari matriks IE disinkronisasi dengan matriks SWOT menghasilkan alternatif strategi yang akan dilakukan pada tahap keputusan. Pada tahap keputusan, dilakukan analisis AHP yang bertujuan menentukan prioritas strategi yang didapatkan. Metode ini dimaksudkan untuk dapat mengorganisasikan informasi dan berbagai keputusan secara rasional (judgement) agar dapat memilih alternatif yang paling disukai (Saaty, 1993).
Pengolahan data dengan metode AHP dapat dilakukan dengan aplikasi perangkat lunak criterium decision plus. Selain itu, dalam aplikasinya, metode ini juga menguji konsistensi berbagai penilaian, khususnya apabila terjadi penyimpangan penilaian yang terlalu jauh dari nilai konsistensi yang sempurna (Marimin, 2004).

\section{HASIL}

\section{Aspek Pasar}

Pada penelitian ini aspek pasar yang dianalisis meliputi permintaan, penawaran, serta bauran pemasaran yang terdiri dari aspek produk, harga, distribusi, dan promosi. Permintaan pasar terhadap produksi susu segar koperasi meningkat antara 30-50 liter setiap harinya, akan tetapi belum dapat terpenuhi karena jumlah produksi susunya yang terus turun. Produk yang dihasilkan koperasi adalah susu segar, yogurt dan susu pasteurisasi. Pendistribusian susu koperasi melalui dua jalur, yaitu dijual langsung kepada konsumen dan dikirim ke KUD Tani Makmur Kecamatan Senduro Kabupaten Lumajang untuk selanjutnya dikirim ke Industri Pengolahan Susu (IPS).

\section{Aspek Teknis}

Aspek teknis meliputi lokasi usaha, peralatan, kapasitas produksi, teknologi yang digunakan dan proses produksi. Lokasi usaha KPGM dekat dengan jalan sehingga kendaraan roda empat bisa melaluinya. Hal ini mendukung kelancaran proses produksi dan juga mendukung kemudahan dalam melakukan proses distribusi produk kepada para konsumen. Lokasi usaha yang jauh dari bahan pakan ampas tahu dan kulit kedelai yang didapatkan dari Mitra Tani 27 tidak terlalu berpengaruh nyata, karena pemenuhan pakan ternak ini dapat diperoleh dengan rumput hasil perolehan peternak.

\section{Aspek Manajemen}

KPGM sudah memiliki struktur organisasi dan juga sudah memiliki komponen-komponen dalam menjalankan fungsi manajemen, yaitu Rapat Anggota Tahunan (RAT), Badan Pengawas (Banwas) dan Badan Pengurus. Ditinjau dari segi administrasi, usaha ini memiliki pencatatan yang jelas dan terperinci atas setiap aktivitas usahanya. 


\section{Aspek Dampak Sosial dan Lingkungan}

Dari aspek lingkungan, walaupun usaha ini belum memiliki izin Analisis Mengenai Dampak Lingkungan (AMDAL) yang menyatakan bahwa keseimbangan lingkungan di daerah sekitar lokasi produksi dapat dijaga, namun hal ini dapat diterima dengan pertimbangan bahwa usaha ini tidak menghasilkam limbah dalam jumlah besar dan limbah yang dihasilkan tidak membahayakan masyarakat. Limbah yang dihasilkan oleh usaha ini dapat dikelola oleh peternak menjadi kompos.

\section{Aspek Hukum}

Ditinjau dari aspek hukum, KPGM sudah memiliki ijin untuk menjalankan usahanya yaitu dengan memiliki Surat Ijin Usaha Perdagangan (SIUP) Nomor 503/513/436.314/2006 dan Tanda Daftar Perusahaan (TDP) 13.07.2.52.00522, serta Nomor Pokok Wajib Pajak (NPWP) 01.947.692.8626.000.

\section{Aspek Ekonomi}

Aspek ekonomi digunakan untuk melihat suatu usaha dari segi arus manfaat melalui keputusan pengalokasian sumber daya yang terbatas ke dalam suatu peluang investasi yang ada sehingga dapat memberikan keuntungan yang maksimal. KPGM memiliki truk yang pada awalnya digunakan untuk mempermudah penyaluran susu segar dari anggota ke Tempat Penampungan Susu (TPS) yang berdomisili di wilayah yang cukup jauh. Ketersediaan fasilitas tersebut juga mempermudah penyaluran pakan konsentrat dari
KPGM kepada anggota. Koperasi juga memperoleh pendapatan tambahan dari sewa truk yang diperoleh pada waktu tertentu, saat mobil sedang tidak digunakan untuk keperluan koperasi. Truk disewa minimal 20 kali dalam sebulan, dengan harga sewa Rp200.000 per hari.

\section{Analisis Lingkungan Internal}

Analisis lingkungan internal pada penelitian ini bertujuan untuk mengevaluasi faktor kekuatan dan kelemahan yang berpengaruh terhadap strategi pengembangan KPGM. Penentuan faktor pada analisis internal mengacu pada hasil analisis deskriptif. Faktor lingkungan internal terdiri dari faktor-faktor kekuatan yang dapat dimanfaatkan dan faktor-faktor kelemahan yang harus diantisipasi oleh Koperasi. Berdasarkan hasil wawancara dan pengisian kuesioner kepada para responden diperoleh hasil evaluasi faktor internal yang dapat dilihat pada Tabel 1.

\section{Analisis Lingkungan Eksternal}

Analisis lingkungan eksternal pada penelitian ini bertujuan untuk mengevaluasi faktor peluang dan ancaman yang berpengaruh terhadap strategi pengembangan KPGM. Penentuan faktor pada analisis eksternal mengacu pada hasil analisis deskriptif. Faktor lingkungan eksternal terdiri dari faktor-faktor peluang yang dapat dimanfaatkan dan faktor-faktor ancaman yang harus diantisipasi oleh koperasi. Berdasarkan hasil wawancara dan pengisian kuesioner kepada para responden diperoleh hasil evaluasi faktor eksternal berdasarkan Tabel 2.

Tabel 1 Matriks IFE

\begin{tabular}{|c|c|c|c|}
\hline Kekuatan & Bobot & Rating & Skor \\
\hline Kegiatan pemasaran yang efektif & 0,075 & 3 & 0,225 \\
\hline Memiliki lokasi strategis & 0,095 & 4 & 0,380 \\
\hline Hubungan kerjasama yang baik dengan IPS & 0,091 & 4 & 0,363 \\
\hline Memiliki alat angkut sendiri & 0,092 & 3 & 0,275 \\
\hline Sistem Quality Control (QC) untuk penerimaan susu & 0,131 & 3 & 0,392 \\
\hline Sistem komputerisasi dalam pencatatan dan penyimpanan data serta informasi & 0,107 & 3 & 0,322 \\
\hline Total & & & 1,957 \\
\hline \multicolumn{4}{|l|}{ Kelemahan } \\
\hline Cakupan wilayah anggota terlalu luas & 0,091 & 2 & 0,182 \\
\hline Produk olahan belum terdaftar BPOM & 0,097 & 2 & 0,195 \\
\hline Modal kerja yang terbatas & 0,125 & 2 & 0,250 \\
\hline Kurangnya loyalitas anggota koperasi & 0,097 & 1 & 0,097 \\
\hline Total & & & 0,724 \\
\hline Total Skor Tertimbang & 1,000 & & 2,681 \\
\hline
\end{tabular}




\section{Analisis Posisi Koperasi}

Matriks IFE dan EFE yang telah diberi bobot dan peringkat serta telah memiliki skor rataan tertimbang, kemudian digabung dalam matriksIEyang menunjukkan posisi kekuatan dan keberhasilan strategi yang telah dijalankan oleh KPGM dalam pengembangannya tersebut dilakukan dengan melihat letak skor pada kuadran-kuadran dalam matriks IE.

Berdasarkan formulasi Matriks IE (Gambar 1), didapatkan skor internal eksternal pada kuadran V (Lima) yang berwarna abu-abu $(2,681: 2,624)$. Dalam kuadran lima ini, KPGM seharusnya menerapkan strategi hold and maintain, yaitu strategi yang diterapkan berupa penetrasi pasar dan pengembangan produk.

\section{Strategi Penetrasi Pasar}

Strategi penetrasi pasar (market penetration) adalah strategi yang mengupayakan pemasaran yang lebih besar dengan cara peningkatan pangsa pasar dari suatu produk di pasar yang sudah ada (David dan Fred, 2012). Penetrasi pasar meliputi peningkatan jumlah karyawan (sales susu), meningkatkan kegiatan promosi dan penguatan merek produk. Penguatan merek produk seperti mendapatkan sertifikat resmi dari BPOM sehingga dapat dipasarkan secara luas bertujuan untuk memperluas target. Mempererat hubungan dengan peternak mitra, IPS dan konsumen. Untuk memposisikan ulang merek produk, ditujukan untuk mencari segmen pasar baru, untuk mempertahankan pendistribusian dimana dapat menjaga hubungan baik antar agen distributor susu segar, IPS dan konsumen. Selain itu perusahaan dapat menerapkan langkah lain. Internal KPGM dapat mencari efisiensi produksi dan pemasaran. Untuk bidang eksternal KPGM dapat mempertahankan pangsa pasar.

Tabel 2 Matriks EFE

\begin{tabular}{|c|c|c|c|}
\hline Peluang & Bobot & Rating & Skor \\
\hline Peningkatan jumlah IPS & 0,092 & 3 & 0,275 \\
\hline Meningkatnya konsumsi susu masyarakat & 0,123 & 4 & 0,494 \\
\hline Perkembangan teknologi yang cepat & 0,095 & 4 & 0,379 \\
\hline Meningkatnya kesadaran masyarakat akan & 0,092 & 3 & 0,275 \\
\hline $\begin{array}{r}\text { Total } \\
\end{array}$ & & & 1,597 \\
\hline \multicolumn{4}{|l|}{ Ancaman } \\
\hline Harga pakan semakin meningkat & 0,094 & 2 & 0,187 \\
\hline Kenaikan harga BBM menyebabkan peningkatan biaya produksi & 0,103 & 2 & 0,206 \\
\hline Kebijakan pemerintah mengenai pembatasan jumlah impor susu & 0,119 & 2 & 0,239 \\
\hline Sulitnya kredit peternakan dari lembaga keuangan & 0,133 & 2 & 0,265 \\
\hline Ketersediaan lahan hijau yang semakin terbatas & 0,130 & 1 & 0,130 \\
\hline $\begin{array}{ll} & \text { Total } \\
\end{array}$ & 1,000 & & 1,027 \\
\hline Total Skor Tertimbang & & & 2,624 \\
\hline
\end{tabular}

Total Nilai IFE yang dibobot

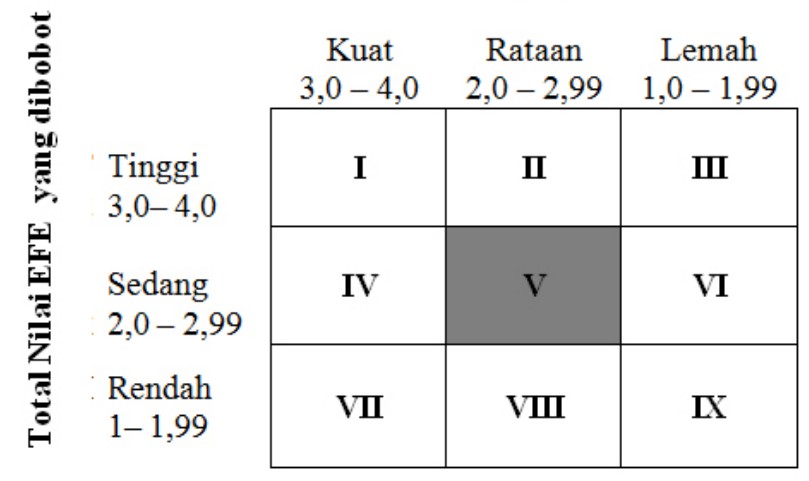

Gambar 1. Matriks IE 


\section{Strategi Pengembangan Produk}

Pengembangan produk merupakan strategi yang dilakukandenganmengupayakanpeningkatanpenjualan dengan cara memperbaiki dan memodifikasi produk yang sudah ada (David dan Fred, 2012). Pengembangan produk ini dilakukan dengan menyempurnakan produk atau mempersiapkan untuk mengeluarkan produk baru. Produk baru atau diversifikasi produk memerlukan permodalan yang besar sehingga dengan bantuan modal maka hal tersebut dapat diselesaikan.

\section{Analisis SWOT}

Analisis SWOT bertujuan mengidentifikasi berbagai faktor secara sistematis untuk merumuskan strategi perusahaan. analisis ini didasarkan pada logika yang dapat memaksimalakan kekuatan (strengths) dan peluang (opportunities). Namun, secara bersamaan dapat meminimalkan kelemahan (weaknesses) dan ancaman (threats). Proses pengambilan keputusan strategik selalu berkaitan dengan pengembangan misi, tujuan, strategi, dan kebijakan perusahaan. oleh karena itu, perencanaan strategis (strategic planner) harus menganalisis faktor-faktor strategik perusahaan (kekuatan, kelemahan, peluang, dan ancaman) dalam kondisi yang ada saat ini. Hasil penelitian, dari faktorfaktor yang menjadi kekuatan, kelemahan, peluang, dan ancaman perusahaan tersebut maka dapat disusun strategi seperti tampak pada Tabel 3.

\section{Analisis AHP}

Hasil wawancara mendalam (in-depth interview) maka dirumuskan suatu struktur/hirarki dengan komponenkomponen yang telah disusun berdasarkan pendapat responden, seperti tampak pada Gambar 2.

Tabel 3. Matriks SWOT

\begin{tabular}{|c|c|c|}
\hline & $\begin{array}{l}\text { KEKUATAN/STRENGTHS (S) } \\
\text { 1. Kegiatan pemasaran yang efektif } \\
\text { 2. Memiliki lokasi strategis } \\
\text { 3. Hubungan kerjasama yang baik } \\
\text { dengan IPS } \\
\text { 4. Memiliki alat angkut sendiri } \\
\text { 5. Sistem QC untuk penerimaan susu } \\
\text { 6. Sistem komputerisasi dalam pen- } \\
\text { catatan dan penyimpanan data serta } \\
\text { informasi }\end{array}$ & $\begin{array}{l}\text { KELEMAHAN/WEAKNESSES W) } \\
\text { 1. Cakupan wilayah peternak mitra/ } \\
\text { anggota terlalu luas } \\
\text { 2. Produk olahan belum terdaftar } \\
\text { BPOM } \\
\text { 3. Modal kerja yang terbatas } \\
\text { 4. kurangnya loyalitas anggota kop- } \\
\text { erasi }\end{array}$ \\
\hline $\begin{array}{l}\text { PELUANG/OPPORTUNITIES(O) } \\
\text { 1. Meningkatnya kzesadaran } \\
\text { masyarakat akan pentingnya hidup } \\
\text { sehat } \\
\text { 2. Meningkatnya konsumsi susu } \\
\text { masyarakat } \\
\text { 3. Perkembangan teknologi yang } \\
\text { cepat } \\
\text { 4. Peningkatan jumlah IPS }\end{array}$ & $\begin{array}{l}\text { STRATEGI S - O } \\
\text { 1. Peningkatan kegiatan promosi den- } \\
\text { gan sosialisasi pentingnya minum } \\
\text { susu (S2 Vs O1, O2, O3, O4) } \\
\text { 2. Efisiensi kegiatan produksi dengan } \\
\text { penyusunan SOP. (S4, S5, S6 Vs } \\
\text { O3) } \\
\text { 3. Penguatan kelembagaan koperasi } \\
\text { (S1, S3 Vs O3) }\end{array}$ & $\begin{array}{l}\text { STRATEGI W - O } \\
\text { 1. Melakukan Pendaftaran produk ke } \\
\text { BPOM (W2 Vs O3) } \\
\text { 2. Melakukan komunikasi intensif } \\
\text { dengan semua anggota koperasi } \\
\text { (W1, W4 Vs O1, O2, O4) } \\
\text { 3. Penguatan permodalan melalui } \\
\text { lembaga keuangan (W5 Vs O2, O4) }\end{array}$ \\
\hline $\begin{array}{l}\text { ANCAMAN/THREATS }(\mathrm{T}) \\
\text { 1. Harga pakan semakin meningkat } \\
\text { 2. Kenaikan harga BBM } \\
\text { menyebabkan peningkatan biaya } \\
\text { produksi } \\
\text { 3. Kebijakan pemerintah mengenai } \\
\text { pembatasan jumlah impor susu } \\
\text { 4. Sulitnya kredit peternakan dari } \\
\text { lembaga keuangan } \\
\text { 5. Ketersediaan lahan hijau yang } \\
\text { semakin terbatas }\end{array}$ & \begin{tabular}{l}
\multicolumn{1}{c}{ STRATEGI S - T } \\
1. Pemanfaatan teknologi tepat guna \\
dalam kegiatan produksi (S1, S2, \\
S3, S4, S5, S6 Vs T1, T2, T5) \\
2. Diversifikasi produk (S2, S3 Vs \\
T3) \\
3. Penguatan permodalan melalui \\
pinjaman selain lembaga keuangan \\
(S1, S3 Vs T4)
\end{tabular} & $\begin{array}{l}\text { STRATEGI W - T } \\
\text { 1. Melakukan koordinasi dengan } \\
\text { pemerintah daerah untuk bantuan } \\
\text { penguatan koperasi dan peternak } \\
\text { (W1, W2, W3, W4 Vs T1, T2, T3, } \\
\text { T4, T5) }\end{array}$ \\
\hline
\end{tabular}




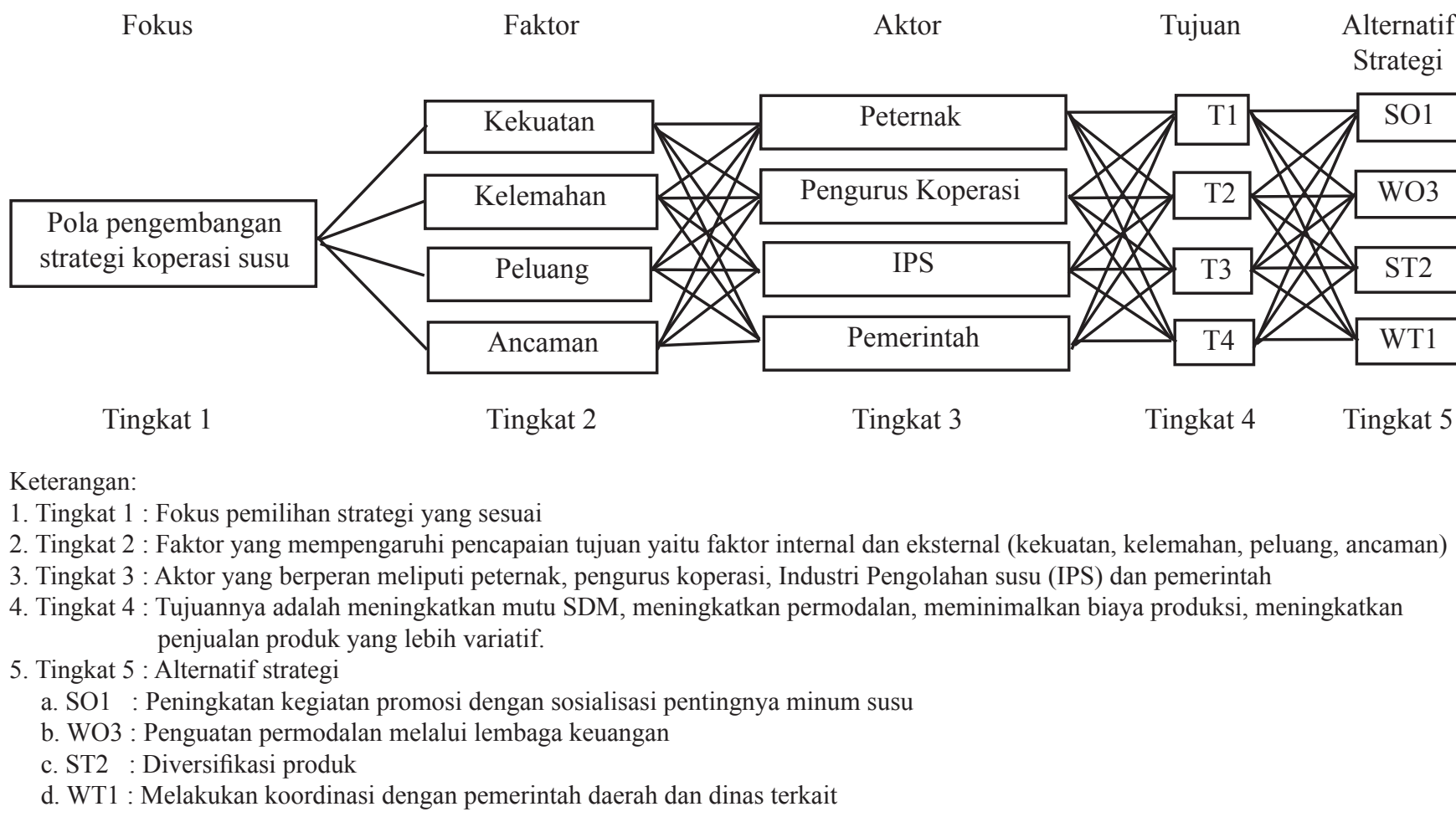

Gambar 2. Struktur AHP

\section{Penentuan Prioritas Strategi}

Setelah dilakukan hirarki, selanjutnya dilakukan perbandingan berpasangan untuk mendapatkan prioritas strategi. Prioritas strategi dilakukan berdasarkan tingkat kepentingan atau urgensi terhadap permasalahan yang dihadapi oleh KPGM, seperti tampak pada Gambar 3. Dengan demikian, dapat dilihat bahwa prioritas alternatif strategi pertama dengan bobot 0,371 adalah strategi penguatan permodalan melalui lembaga keuangan, prioritas kedua dengan bobot 0,344 adalah strategi peningkatan kegiatan promosi dengan sosialisasi pentingnya minum susu, prioritas ketiga dengan bobot 0,174 adalah strategi diversifikasi produk, dan prioritas keempat dengan bobot 0,111 adalah strategi peningkatan koordinasi dengan pemerintah daerah serta Dinas Peternakan dan Dinas UMKM.

\section{KESIMPULAN DAN SARAN}

\section{Kesimpulan}

Simpulan dari hasil penelitian adalah faktor strategik yang menjadi kekuatan utama dengan kepentingan relatif tertinggi adalah sistem Quality Control (QC) untuk peneriman susu dari peternak. Faktor strategik kelemahan utama yang memiliki kepentingan relatif tertinggi adalah keterbatasan modal. Faktor strategik peluang yang memiliki kepentingan relatif tertinggi adalah kesadaran masyarakat akan hidup sehat. Faktor strategik yang menjadi ancaman dengan kepentingan relatif tertinggi adalah sulitnya kredit peternak dari lembaga keuangan.

Alternatif strategi yang dapat diterapkan di KPGM adalah peningkatan kegiatan promosi dengan sosialisasi pentingnya minum susu, efisiensi kegiatan produksi dengan penyusunan Standard Operational Procedure (SOP), penguatan kelembagaan koperasi, melakukan pendaftaran produk ke Badan Pengawas Obat dan Makanan (BPOM), melakukan komunikasi intensif dengan semua anggota koperasi, pemanfaatan teknologi tepat guna dalam kegiatan produksi, diversifikasi produk, penguatan permodalan melalui pinjaman selain lembaga keuangan dan melakukan koordinasi dengan pemerintah daerah untuk bantuan penguatan koperasi dan peternak.

Hasil analisis AHP, strategi yang menjadi prioritas utama adalah penguatan permodalan melalui lembaga keuangan, peningkatan kegiatan promosi dengan sosialisasi pentingnya minum susu, diversifikasi produk, dan melakukan koordinasi dengan pemerintah daerah serta Dinas Peternakan dan Dinas UMKM. 


\begin{tabular}{|c|c|c|}
\hline Alternatif strategi & Value & Decision Scores \\
\hline SO1 & 0,344 & \\
\hline WO3 & 0,371 & \\
\hline ST2 & 0,174 & \\
\hline WT1 & 0,111 & \\
\hline
\end{tabular}

Gambar 3. Prioritas strategi berdasarkan teknik AHP

\section{Saran}

Saran yang diberikan melalui kajian penelitian bagi peneliti selanjutnya, yaitu perlu dilakukan penelitian lebih mendalam tentang strategi pemasaran serta perbaikan tata kelola koperasi pada KPGM. Bagi pemerintah, agar memberikan akses kemudahan kepada para peternak yang menjadi anggota koperasi untuk menerima bantuan dengan kredit lunak. Selanjutnya, bagi pengelola koperasi, disarankan meningkatkan mutu pelayanan kepada anggota koperasi dan menjalin kerjasama dengan Pemda serta Dinas Peternakan dan Dinas UMKM dalam bentuk pemberian pelatihan yang bersifat teknis.

\section{DAFTAR PUSTAKA}

Adinata KI, Sari AI, Rahayu ET. 2012. Strategi pengembangan usaha sapi potong di Kecamatan Mojolaban Kabupaten Sukoharjo. Tropical Animal Husbandry 1(1): 24-32.

Azhim F, Salengke, Zainal. 2014. Strategi pengembangan industri pengolahan susu sapi di Kabupaten Sinjai, Sulawesi Selatan. Jurnal Sains dan Teknologi 14(2): 162-171.

Anoraga P, Widiyanti N. 2007. Dinamika Koperasi. Jakarta: Rineka Cipta.

Arikunto S. 2006. Prosedur Penelitian Suatu Pendekatan Praktik. Jakarta: Rineka Cipta.

Baga LM. 2005. Revitalisasi koperasi petani. Agrimedia 10(2): 38-46.

David, Fred R. 2012. Manajemen Strategis: Konsep. Jakarta: Salemba Empat.

Muzammil AR. 2005. Analisis strategi pemasaran susu segar dan produk olahannya oleh koperasi di
Jawa Timur (studi kasus di koperasi peternakan sapi perah KPSP Setia Kawan Nongkojajar Pasuruan [tesis]. Bogor: Manajemen Bisnis Institut Pertanian Bogor.

Sarpintono. 2013. Strategi pengembangn sistem agribisnis peternakan sapi perah di Provinsi Bengkulu [tesis]. Bengkulu: Universitas Bengkulu.

Kasim SN, Sirajuddin SN, Irmayani. 2011. Strategi pengembangan usaha sapi perah di Kabupaten Enrekang. Jurnal Agribisnis 10(3): 81-97.

[Kemenperin] Kementerian Perindustrian. 2013. Konsumsi susu masih 11.09 liter per kapita. http://www.kemenperin.go.id/artikel/8890. [20 November 2014].

Marimin. 2004. Teknik dan Aplikasi Pengambilan Keputusan Kriteria Majemuk. Jakarta : PT. Gramedia Widiasarana Indonesia.

Saaty TL. 1993. Pengambilan Keputusan Bagi Para Pemimpin: Proses Hierarki Analitik untuk Pengambilan Keputusan dalam Situasi yang Kompleks. Jakarta: PT Binaman Pressindo.

Sukardi. 2009. Metodologi Penelitian Pendidikan: Kompetensi dan Praktiknya. Jakarta: Bumi Aksara.

Supriatna S, Aminah M. 2014. Analisis strategi pengembangan usaha kopi luwak (studi kasus UMKM Careuh Coffee Rancabali-Ciwidey, Bandung). Jurnal Manajemen dan Organisasi. 5(3): 227-244.

Tampubolon PFTP, Hermanto S, Muladno, Machfud. 2011. Strategi pengembangan usaha sapi perah skala mikro berwawasan lingkungan di Kabupaten Subang, Jawa Barat. Manajemen IKM 6(2): 105-110. 